\title{
Analysis of anti-collapse capability of such dolomite
}

\author{
Xue-Peng Wang, Hua-Shu Yang* and Wei Dong \\ Kunming University of Science and Technology, Kunming 650051, China \\ E-mail: yhs005914@qq.com \\ *Corresponding author: Hua-Shu YANG
}

\begin{abstract}
Crag lurks danger to thorpe and road, which would bring on momentous losses of people and riches in case of collapse. Applicability of correlative theories and finite element method was studied. In allusion to specifically dolomite's occurrences and by virtue of data rooting in autoptic reconnaissance and field test, mathematical model was educed for reliability assessment. Crag stabilities were calculated at three varieties of load combinations. Reinforcement advice was put forward for such dolomite based on qualitative analysis and quantitative analysis. This scheme may be used for preventing analogous geologic hazard. The course of modeling and analyzing may be a referrence in the study realm of crag collapse.
\end{abstract}

Keywords: Reliability assessment, Crag, Dolomite, Anti-collapse

\section{Introduction}

Profit from development of society and economy, the process of montane building is speeding on. The constructions of road, railway and water power engineering increase amount of dangerous rock mass, and more and more attention is paid at preventive disposing of dangerous rock mass.

Latent geologic hazard from dangerous rock mass exists in many places, and researches at dangerous rock mass is indispensable work to solve these disaster. Dangerous rock mass's stability were analysed and evaluated in allusion to such dolomite, then generating probability of geologic hazard was calculated and preventive treatment project was put forward.

\section{Distinguishing of Dangerous Rock Mass}

\subsection{Landform character}

Discussional area belongs to river valley's slope in Yunnan of China, which is situated on east bank's terrace of Qingzhu river's back rim, and some bedrock appears. The height of slope toe is $788 \mathrm{~m}$, geography height difference is $290 \mathrm{~m}$. 
The slope of the ridge's both side is very steep, natural slope angle is $30-70^{\circ}$, plants grow well, shrub are in large number and other short jungles, there are dangerous rock masses which are in danger in certain places. Top of the slope is rock slope which is bare, and the lithology is dolomitic limestone. There groups of structural plane mainly develop, among them occurrence of bedding surface is $\mathrm{N} 81^{\circ} \mathrm{W}$ and $\mathrm{SW} \angle 44^{\circ}$, the occurrence of the other two structural plane respectively is $\mathrm{S} 6^{\circ} \mathrm{E}$ and $\mathrm{SW} \angle 72^{\circ}, \mathrm{N} 84^{\circ} \mathrm{W}$ and $\mathrm{NE} \angle 57^{\circ}$. Middle of the slope mainly is residual-slope accumulation which accumulates by hydraulic parameters of broken stone soil, toe of slope is slope wash of collapse, and the lithology is medium dense clay mixed with broken rubble. The front rim of toe of slope is sandy gravel's accumulation from the first terrace of Qingzhu river, which thickness is $2-3 \mathrm{~m}$.

\subsection{Geology summary}

This dangerous rock mass is located in middle slope of Dongshan mountain's southern ridge and back rim's center coordinates are $\mathrm{X}=522507.3679$, $\mathrm{Y}=3607579.3073$. After preliminary survey, this dangerous rock mass collapsed in " 5.12 " earthquake, the main direction is $\mathrm{S} 20^{\circ} \mathrm{W}$, the length of this mass is $9 \mathrm{~m}$, and its width is $8 \mathrm{~m}$. Front rim's altitude is $872.5 \mathrm{~m}$ for this mass, which back rim altitude is $882 \mathrm{~m}$, so height difference is $9.5 \mathrm{~m}$, and slope gradient is $50^{\circ}$. According to trial trench: unloaded zone's thickness is about $3 \mathrm{~m}$, and rock mass's volume is about $216 \mathrm{~m}^{3}$, so it is a small collapse mass. The mass's toe of slope is the talus which is formed by caving rock mass after earthquake, the length of the talus is $8 \mathrm{~m}$, its width is $9 \mathrm{~m}$, slope gradient is $45^{\circ}$. Some rock rolled down to gentle slope, and stopped on the upland. This landslip height difference reached $50 \mathrm{~m}$ in "5.12" earthquake of Yunnan.

\subsection{Engineering indices of such dolomite}

Through engineering geological investigation and test, physical and mechanical parameters of dangerous rock mass were get. After overall consideration, engineering indexes in Table 1 were used as calculation parameters in this example.

Table 1 Engineering indices of such dolomite

\begin{tabular}{cccccc}
\hline Water content & Cohesion & Internal friction angle Unit weight & Compressive strengt & Tensile strength \\
$\boldsymbol{\omega}[\%]$ & $c[\mathrm{kPa}]$ & $\boldsymbol{\varphi}\left[{ }^{\circ}\right]$ & $\gamma\left[\mathrm{kN} / \mathrm{m}^{3}\right]$ & $\sigma_{+}[\mathrm{Mpa}]$ & $\boldsymbol{\sigma}_{\text {- }[\mathrm{Mpa}]}$ \\
\hline nature & 42 & 34 & 24.4 & 64.6 & 3.876 \\
saturation & 38 & 31 & 25.0 & 37.4 & 2.244 \\
\hline
\end{tabular}




\section{Analysing at Crag Stability}

There are multifarious analytical method about rock stability, utmost-equilibrium method and finite element method are primary among them. Benefits of calculation method which is built by using utmost-equilibrium theory: don't need to consider the relationship between stress and strain, which is easy to certain the force, and needed calculation parameters is not much. As well as calculation result would reflect real stability situation of dangerous rock mass. Finite element method could reflect the relationship between stress and strain of the mass very well. It would not be limited by the shape and uneven material of slope, so it is a perfected method to analyse the stability of dangerous rock mass. But it is difficult to build model by finite element method and calculation process is very lengthy.

\subsection{Modified algorithm}

According to survey and constructional plane at geological structure, rock stratum tendency of this mass is almost similar to slope aspect, and mass dip matches the slope angle. So it is obvious that the mass is unfavorable geology of consequent landslide, stability is bad. And because the rock is influenced by other groups joint structural planes that is opening type, rock is broken. Because of the effect of external force like earthquake and rain, two steeper groups of constructional pane which tend towards outside of slope became less crowded, so earthquake would lead slumping collapse easily at dangerous rock mass.

To be shown in Fig.1, as a check calculation model of dangerous rock mass's slumping, its dip was $\beta\left[^{\circ}\right]$ and strength parameter was $c$ and $\varphi$. $W$ represented deadweight of the mass $[\mathrm{kN}], P$ represented horizontal seismic force on the mass $[\mathrm{kN}]$. Following results would be gotten by decompose master structure plane [1]:

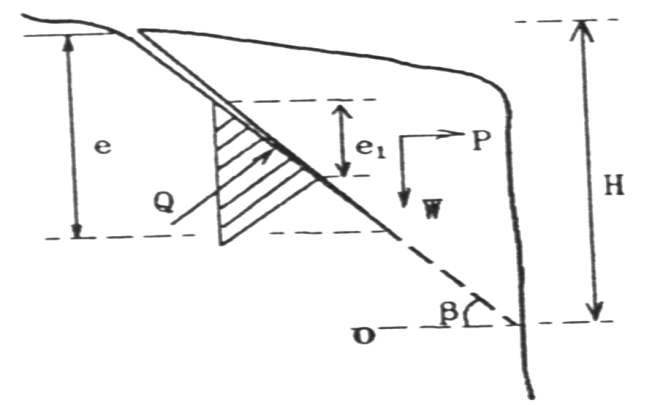

\section{Fig.1 calculation model of slumping}

To normal component $N=W \cos \beta-P \sin \beta$ And to tangential component $T=W \sin \beta+P \cos \beta$. 
By tentative, $N$ and $T$ would distribute along the main control structure plane evenly, so average normal stress $\sigma$ and average shear stress $\tau$, and shear strength $\tau_{f}$ on the surface of the crack should respectively be:

$\sigma=N / H / \sin \beta, \tau=T / H / \sin \beta, \tau_{f}=\sigma \operatorname{tg} \varphi+c$.

So stability coefficient $\left(K_{f}\right)$ should be:

$K_{f}=[(W \cos \beta-P \sin \beta-Q) \operatorname{tg} \varphi+c H / \sin \beta] /(W \sin \beta+P \sin \beta)$.

As condition I, water filling depth was $1 / 3$ the depth of master structural plane, so $e_{1}=e / 3$. Fissure water pressure $(Q)$ and stability coefficient $\left(K_{f}\right)$ should respectively be:

$Q=\gamma_{w} e^{2} / 18, K_{f}=[(W \cos \beta-Q) \operatorname{tg} \varphi+c H / \sin \beta] /(W \sin \beta)$.

As condition II, water filling depth was $2 / 3$ the depth of master structural plane, so $e_{1}=2 e / 3$. Fissure water pressure $(Q)$ and stability coefficient $\left(K_{f}\right)$ should respectively be:

$Q=2 \gamma_{w} e^{2} / 9, K_{f}=[(W \cos \beta-Q) \operatorname{tg} \varphi+c H / \sin \beta] /(W \sin \beta)$.

As condition III, water filling depth was $1 / 3$ the depth of master structural plane, so $e_{1}=e / 3$. Fissure water pressure $(Q)$ and stability coefficient $\left(K_{f}\right)$ should respectively be:

$Q=\gamma_{w} e^{2} / 18, K_{f}=[(W \cos \beta-P \sin \beta-Q) \operatorname{tg} \varphi+c H / \sin \beta] /(W \sin \beta+P \cos \beta)$.

Symbolic meanings were defined as follows: $H$-slope height; $c$ - cohesion of slope materials; $\varphi$ - internal friction angle; $\gamma_{w}$ - specific gravity of water; $W-$ gravity of rock-soil mass; $P$ - horizontal seismic force; $\beta$ - fracture surface inclination.

\subsection{Working conditions and load combinations}

If the dangerous rock mass was quantificational calculated, working conditions and load combinations of slope should be take into consideration. According to criterion and enough engineering examples, three kinds of conditions and load combinations were considered.

Working condition I was assumed as natural situation. Load combination was dead weight + fissure water pressure, or dead weight and 1/3 water pressure when fissure was filled water in natural situation. 
Working condition II was assumed as natural + rainstorm situation. Load combination was dead weight + fissure water pressure, or dead weight and 2/3 water pressure when fissure was filled water in rainstorm situation.

Working condition III was assumed as natural + earthquake situation. Load combination was dead weight + fissure water pressure (natural situation) + earthquake force (checking condition), or dead weight and 2/3 water pressure when fissure is filled water in rainstorm situation [2].

Working conditions and load combinations for stability calculation at such dolomite would be considered according to the tree working conditions above.

\subsection{Other parameters}

According to reconnaissance data, local experience and parameter inversion, shear strength of each structural plane would be gotten by taking value synthetically (parameter values under water saturated state is 0.8-0.9 times of parameters under natural situation).

Parameter values are different for the difference of structural plane. The value range of structural plane parameters is $c=30-50 \mathrm{kPa}, \varphi=25-35^{\circ}$. Discussional structure plane parameters were shown in Table 1 as a actual example.

\section{Reliability Assessment at Dolomite Crag}

With stability coefficient of the mass, crag stability was divided into three situation by Hong-Kai CHEN etc, including steady, basically steady, and unsafe state [3], shown in Table 2.

\subsection{Qualitative analyse}

According as scene exploration and analysis of stereographic projection, this dangerous rock mass collapsed in "5.12" earthquake. Now there are much dangerous rubbles to remain on the slope, so the slope is very unsafe state. The mass is not very stable, and it would collapse when rainstorm or earthquake occurs in the future.

Table 2 Reliability classification of collapse index $(F)$

\begin{tabular}{cccc}
\hline collapse type & steady state & basically steady & unsafe state \\
\hline slumping & $F>1.3$ & $1.3-1.0$ & $F<1.0$ \\
\hline
\end{tabular}




\subsection{Quantitative Research}

By the algorithm (Eq.1-5) discussed above and calculation parameters shown in table1, it is certain that collapse type of this mass is slumping. Next the mass would be calculated in stability, analysed and evaluated by calculation method of failure mode on slumping type with exploration profile.

In working condition I, $K_{f}=1.32$. In working condition II, $K_{f}=1.12$. And in working condition III, $K_{f}=1.11$.

The $K_{f}$ namely is the $F$ shown in Table 2 with this disquisition. Stability coefficient $\left(K_{f}\right)$ of the mass would be 1.32 under working condition I (natural condition), it is in stability condition. The stability coefficient would be 1.12 under working condition II (rainstorm condition), it's not very stable. The stability coefficient would be 1.11 under working condition III (earthquake condition), it is frailest. So this result accorded with qualitative analyse in substance.

\section{Conclusions}

The crag now is in utmost-equilibrium state. And with each crack extending, the stability would get worse. The block diameter of dangerous rock is big, so rock's impact force would be strong. Fallen height difference is large, the slant range is long and terrain gradient is big, so influencing width of landslip could reach $80 \mathrm{~m}$. If this crag is not in stability, collapse in big area would occur and nearby people's life and property would be threatened.

It's suggested that the crag might be excavated in order to reduce the danger, and passive protective nets could also be considered. The active protective nets could be applied to control measure [4-7].

Because advisement is inadequate at simplification of boundary condition and mechanics traits, the coherence of numerical simulation and actual crag is usually poor. Crag's stability was calculated quantificationally based on data rooting in autoptic reconnaissance and field test, so creditability of safety appraisal is preferable. For theories educed by stability study are manifold and distinctive, proper analysis means should be chosen to appraise crag's safety by rock sort, occurrence, physics and mechanics parameters etc, so strengthening at weakness could be achieved. The harvest of this disquisition had be used for actual prevention engineering of geologic hazard, and effect was better as a whole.

\section{Acknowledgement}

This work was financially supported by The National Natural Science Foundation of China (Grant No.41462013; No.50869003; No.51069003), and by Scientific 
Research Foundation of Education Department of Yunnan Province, China (Grant No. 2015Y072).

Corresponding author: Yang Huashu, professor, doctoral tutor, and a academic leaders of Yunnan Province, China. E-mail: yhs005914@qq.com.

\section{References}

[1]. Hong-Kai CHEN, Xue-Fu XIAN, Hong-Mei TANG, etc. Stability analysis method for perilous rock, J. Journal of Applied Mathematics and Mechanics. 02 (2009) 278-282. (in Chinese)

[2]. Shuan-Cheng GU, Shi-Bing ZHANG. Application of ANSYS in the stability analysis of the high dangerous rock mass, J. Journal of Xi'an University of Science and Technology. 04 (2003) 375-378. (in Chinese)

[3]. Hong-Kai CHEN, Hong-Mei TANG, Rong WANG. Calculation method of stability for unstable rock and application to the Three Gorges reservoir, J. Chinese Journal of Rock Mechanics and Engineering. 04 (2004) 614-619. (in Chinese)

[4]. Wei-Min LI, Hong-Han GENG. Stability analysis of the dangerous rock mass in FAST location, J. Geotechnical Investigation \& Survrying. S1 (2010) 578-587. (in Chinese)

[5]. Yin-Hui LUO, Bin HU, Rong-Hua ZHU, etc. Formation mechanism and control method of collapse, J. Exploration Engineering on West of China. 12 (2008) 1-3.(in Chinese)

[6]. Hong-Kai CHEN, Hong-Mei TANG. Method to calculate fatigue fracture life of control fissure in perilous rock, J. Applied Mathematics and Mechanics. 05 (2007) 643-649.

[7]. Guo-Xing CHEN, Hua PAN, Hui LONG, etc. Dynamic constitutive model for soils considering asymmetry of skeleton curve, J. Journal of Rock Mechanics and Geotechnical Engineering. 05 (2013) 400-405. 